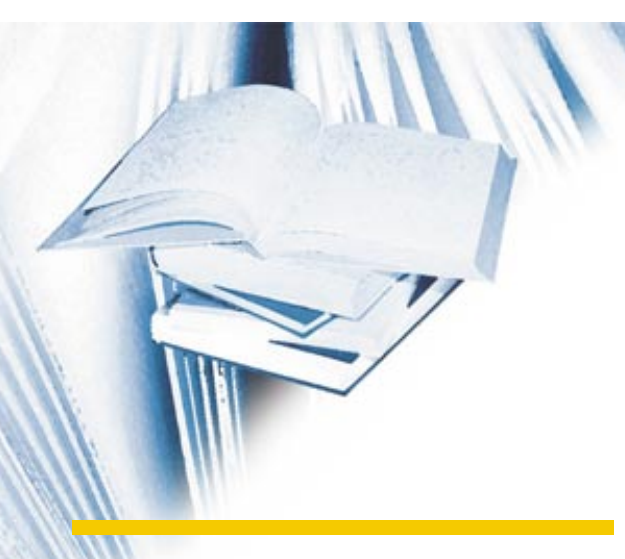

\section{Basic Principles in Applied Catalysis}

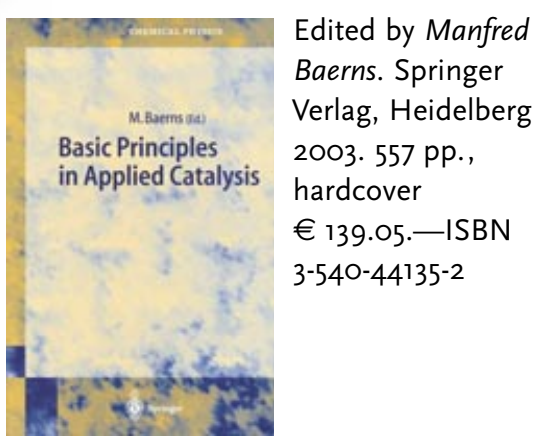

This is a well-written and valuable book, which gives a good flavor of the many important aspects of applied catalysis. The individual chapters are written by well-known (mainly German) catalysis experts. The quality of their contributions ranges from outstanding to good. The book can be seen as an excellent introduction to the field for chemists with little experience in catalysis. On the other hand, the title of the book is over-ambitious, since it gives the potential buyer the impression that all principles behind applied catalysis will be discussed, including the basic steps governing catalysis, such as the nature of the active sites, unraveling of reaction mechanisms and deactivation routes, mass transport phenomena, and reactor design. What the book really does is to provide the reader with a good idea of the importance of catalysis for modern society, together with detailed information about relevant catalytic processes and conceptual information about the preparation and use of solid catalysts in an industrial environment. Apart from a few short exceptions, the book is easy to read and contains a lot of references for further reading. It is fairly complete in its coverage, since it discusses the most important types of catalysts, processes, catalyst preparation, deactivation, and characterization, although some topics are not covered. Chapters on structured catalysts, mass transfer, and chemical reactors are missing or could be improved.

The first part of the book is clearly the best. The introduction by Schmidt gives a very good feel for the (commercial) importance of catalysis and the most important aspects and applications. The next part, containing four chapters on selected reactions in heterogeneous catalysis, presents a valuable background on the role of catalysis in important large-scale processes, and reading this part is also highly recommended. The quality of the next parts of the book is somewhat mixed. It contains very good parts that give the basics on the preparation of catalysts. The part on in situ catalyst characterization is highly relevant, although we did not much like the very long table containing a list of commonly used characterization techniques. Such a comprehensive table is not really of great value for nonspecialists. A more limited selection providing more information on specific studies would have been better. The book also contains a part on catalytic reaction engineering. This part includes an interesting chapter on the deactivation of catalysts. This is another well-written chapter, in which a topic is discussed that is without doubt vital for commercial catalytic processes, and is often overlooked in academic research and publications. It discusses deactivation mechanisms, kinetics, and the relevance to important processes. The same part of the book contains the only chapter that is less easy to read, that on the kinetics of heterogeneous catalysis. On one hand, the chapter goes too deeply into the topic by discussing basic fundamentals, whereas on the other hand it fails to discuss the different types of kinetics that are commonly found for reactions of particular kinds, nor does it discuss the basic rules on how to determine catalytic kinetics. The (mass-transfer) problems one often encounters when determining catalytic kinetics are also not discussed, as already mentioned above.

In summary, the book provides an excellent introduction to the importance of the field of applied catalysis. It is generally well-written and almost complete, and the quality of presentation is excellent, with the exception of about 10 figures (out of 170). For people working or doing research in applied catalysis, most of the information in the book may already be familiar, and the book is probably too general, although it can be used as a quick source of references on selected topics. For chemists interested in catalysis, for scientists engaged in fundamental research on catalysis, and for users of catalysts who wish to learn about key aspects affecting their performance, reading this book is highly recommended.

\section{Xander Nijhuis, Bert Weckhuysen}

Department of Inorganic Chemistry and Catalysis

Utrecht University (The Netherlands)

\section{DOI: 10.1002/anie.200485195}

\section{Computational Chemistry}

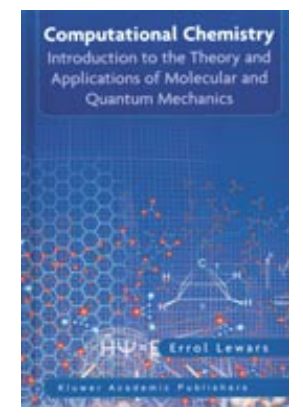

Introduction to the Theory and Applications of Molecular and Quantum Mechanics. By Errol G. Lewars. Kluwer Academic Publishers, Dordrecht 2003. 47 pp., softcover $€ 71.00 .-\mathrm{ISBN}$ $1-4020-7422-0$

In their effect on novices, there may be certain parallels between computational chemistry and flying: many newcomers feel magically attracted, others show their deep respect, and still others keep clear of it. Probably only a few of the young flying enthusiasts will stay the course to get to know the true promise of aviation, after spending several years on analytical mechanics, cartography, electrical and mechanical engineering, then flying paper darts and model aircraft, until finally they are ready for their maiden flight. It goes without 